\title{
Overexpression of Septin1: Possible contribution to the development of oral cancer
}

\author{
YOSHIKUNI KATO $^{1}$, KATSUHIRO UZAWA ${ }^{1,2}$, NOBUHARU YAMAMOTO ${ }^{3}$, YUKINAO KOUZU ${ }^{1}$, \\ HIROFUMI KOIKE ${ }^{1}$, MASASHI SHIIBA ${ }^{2}$, HIROKI BUKAWA ${ }^{2}$, HIDETAKA YOKOE ${ }^{2}$, \\ TAKAHIKO SHIBAHARA ${ }^{3}$ and HIDEKI TANZAWA ${ }^{1,2,4}$
}

\begin{abstract}
${ }^{1}$ Department of Clinical Molecular Biology, Graduate School of Medicine, Chiba University, 1-8-1 Inohana, Chuo-ku, Chiba 260-8670; ${ }^{2}$ Division of Dentistry and Oral-Maxillofacial Surgery, Chiba University Hospital, 1-8-1 Inohana, Chuo-ku, Chiba 260-8670; ${ }^{3}$ Department of Oral and Maxillo-Facial Surgery, Tokyo Dental College, 1-2-2 Masago, Mihamaku-ku Chiba 261-8502; ${ }^{4}$ Center of Excellence (COE) Program in The 21st Century, Graduate School of Medicine, Chiba University, 1-8-1 Inohana, Chuo-ku, Chiba 260-8670, Japan
\end{abstract}

Received February 26, 2007; Accepted April 15, 2007

\begin{abstract}
Our previous study using proteomic profiling demonstrated significant up-regulation of Septin1, a conserved family of GTPase proteins, in oral squamous-cell carcinoma (OSCC)-derived cell lines. In the current study, to determine the potential involvement of Septin 1 in oral carcinogenesis, we evaluated the state of septin 1 protein/ mRNA expression in OSCC-derived cell lines, oral premalignant lesions (OPLs), and primary OSCCs. A significant $(\mathrm{P}<0.05)$ increase in Septin1 expression was evident in all OSCC-derived cell lines examined compared to human normal oral keratinocytes (HNOKs) and OPLs. In immunohistochemistry, while the vast majority of the OSCCs (89\%) were positive for Septin1, no immunoreaction was observed in corresponding normal tissues and OPLs. In addition, real-time quantitative reverse transcriptase-polymerase chain reaction (QRT-PCR) data were consistent with the protein expression status. These results suggest that Septin 1 expression could contribute to cancer progression, proliferation, or both, and that Septin 1 may be a potential diagnostic marker of highly active cancer and a therapeutic target for OSCCs.
\end{abstract}

\section{Introduction}

Oral squamous-cell carcinomas (OSCCs), the most common cancer of the head and neck, accounts for over 300,000 new cancer cases worldwide annually (1). With the currently available clinical assessment and treatment methods, patients are often diagnosed in the late stage of the disease, and the

Correspondence to: Dr K. Uzawa, Department of Clinical Molecular Biology, Graduate School of Medicine, Chiba University, 1-8-1 Inohana, Chuo-ku, Chiba 260-8670, Japan

E-mail: uzawak@faculty.chiba-u.jp

Key words: Septin1, potential markers, oral squamous cell carcinoma, cytokinesis survival rate has not improved substantially. This highlights the need for continued efforts to discover suitable biomarkers for early diagnosis of the disease and to understand the disease pathogenesis as a first step toward improving treatment. Elucidation of the genetic changes leading to the development of OSCCs will probably result in improved molecular assays for the early diagnosis of, therapy for, and improved prognosis of this cancer. The availability of biomarkers of malignancy would also be a key factor for monitoring cancer recurrence and evaluating the efficacy of novel treatment.

The proteomic study includes post-translational modifications such as acetylation, ubiquitination, phosphorylation, or glycosylation $(2,3)$. Proteomic methods detect the functioning units of expressed genes using protein fingerprinting $(4,5)$. In addition, many cancer biomarkers are a manifestation of differences in post-transcriptional splicing, post-translational modifications, or both. Thus, proteomic tools are used increasingly in the post-genomic era to discover new cancer biomarkers. This information will likely prove to be crucial in cancer prognosis, diagnosis, prevention, and therapy, with the ultimate goals being therapeutic target discovery, rational drug design, and identification of early-detection surrogate biomarkers $(5,6)$.

In our previous study, using a fluorescent two-dimensional differential in-gel electrophoresis (2-D-DIGE) system and matrix-assisted laser desorption/ionization time-of-flight mass spectrometry (MALDI-TOF/MS), we compared protein expression profiles in human normal oral keratinocytes (HNOKs) and OSCC-derived cell lines and identified several OSCC-associated proteins (7). Among them, the protein, Septin1, was found to be a putative OSCC-related protein. The current study focused on the state of septin1 expression at protein/mRNA level in OSCC-derived cell lines, human primary OSCCs, and oral premalignant lesions (OPLs).

\section{Materials and methods}

Tissue specimens and cell lines. Tissue samples were obtained during surgical resection from 85 unrelated Japanese patients 
Table I. Clinical of pathological characteristics of patients and their tumor.

\begin{tabular}{|c|c|c|c|c|}
\hline \multirow[b]{2}{*}{ Clinical classification } & \multirow[b]{2}{*}{ Total } & \multicolumn{2}{|c|}{ Immunostaining results [no. of patients $(\%)$ ] } & \multirow[b]{2}{*}{ P-value } \\
\hline & & septin1 $(+)$ & septin1 (-) & \\
\hline Age at surgery & & & & 0.665114 \\
\hline$<60$ & 24 & $21 \quad(88)$ & $3(12)$ & \\
\hline $60-70$ & 25 & $23(92)$ & $2(8)$ & \\
\hline$\geq 70$ & 36 & $33(92)$ & $3(8)$ & \\
\hline Gender & & & & 0.891534 \\
\hline Male & 55 & $50 \quad(91)$ & $5(9)$ & \\
\hline Female & 30 & $27 \quad(90)$ & $3(10)$ & \\
\hline T-primary tumor & & & & 0.0156749 \\
\hline $\mathrm{T} 1$ & 6 & $3(50)$ & $3(50)$ & \\
\hline $\mathrm{T} 2$ & 37 & $34 \quad(92)$ & $3(8)$ & \\
\hline $\mathrm{T} 3$ & 18 & $16(89)$ & $2(11)$ & \\
\hline $\mathrm{T} 4$ & 24 & $24(100)$ & 0 & \\
\hline N-regional lymph node(s) & & & & 0.70461 \\
\hline N (-) & 54 & $48 \quad(89)$ & $6(11)$ & \\
\hline $\mathrm{N}(+)$ & 31 & $29(94)$ & $2(6)$ & \\
\hline Stage & & & & 0.155804 \\
\hline I & 5 & $2(50)$ & $3(50)$ & \\
\hline II & 17 & $17(100)$ & 0 & \\
\hline III & 16 & $14(88)$ & $2(12)$ & \\
\hline IV & 47 & 44 (94) & $3(6)$ & \\
\hline Histopathological type & & & & 0.0168169 \\
\hline Well differentiated & 55 & $53 \quad(97)$ & $2(3)$ & \\
\hline Moderately differentiated & 24 & $19(80)$ & $5(20)$ & \\
\hline Poorly differentiated & 6 & $5 \quad(83)$ & $1(17)$ & \\
\hline Tumor site & & & & 0.164478 \\
\hline Gingiva & 25 & $25(100)$ & 0 & \\
\hline Tongue & 39 & $33 \quad(85)$ & $6(15)$ & \\
\hline Buccal mucosa & 8 & $8(100)$ & 0 & \\
\hline Oral floor & 8 & $7(88)$ & $1(12)$ & \\
\hline Oropharyngeal isthmus & 4 & $3(75)$ & $1(25)$ & \\
\hline Lower lip & 1 & $1(100)$ & 0 & \\
\hline
\end{tabular}

with primary SCC of the oral cavity who were treated at Chiba University Hospital between 1998 and 2005 (Table I) and from 33 unrelated Japanese with leukoplakia of the oral cavity who were treated at the Tokyo Dental College Hospital between 2005 and 2006 (Table II). Tumors and patientmatched normal epithelium were obtained intraoperatively at Chiba University Hospital after the patients provided informed consent for a protocol approved by the institutional review board of Chiba University.

The resected tissues were divided into two parts, one of which was frozen immediately after careful removal of the surrounding normal tissues and stored at $-80^{\circ} \mathrm{C}$ until protein isolation; the second part was fixed in $10 \%$ buffered formaldehyde solution for pathologic diagnosis and immunohistochemical staining. Histopathologic diagnosis of each neoplastic tissue was performed according to the World Health Organization criteria by the Department of Pathology, Chiba University Hospital. Clinicopathological staging was determined by the TNM classification of the International Union against Cancer. All patients had SCC that was confirmed histologically, and tumor samples were checked to ensure that tumor tissue was present in $>80 \%$ of the specimens. The 
Table II. Patients and their OPLs.

\begin{tabular}{lr}
\hline Clinical classification & No. of patients $(\%)$ \\
\hline Age at surgery & $16(49)$ \\
$<60$ & $10(30)$ \\
$60-70$ & $7(21)$ \\
$\geq 70$ & \\
Gender & $18(55)$ \\
Male & $15(45)$ \\
Female & \\
Leukoplakia site & $13(40)$ \\
Gingiva & $10(30)$ \\
Tongue & $2(6)$ \\
Buccal mucosa & $7(21)$ \\
Plate & $1(3)$ \\
Lips & \\
\hline
\end{tabular}

OSCC-derived cell lines used in this study were HSC-2, HSC-3, HSC-4, HO-1-N-1, KON (Human Science Research Resources Bank, Osaka, Japan), and OK92 (established from carcinoma of the tongue in our department) (8). All OSCCderived cell lines were grown in Dulbecco's modified Eagle's medium/F-12 HAM (Sigma-Aldrich Co., St. Louis, MO, USA) supplemented with $10 \%$ fetal bovine serum (Sigma) and $50 \mathrm{U} / \mathrm{ml}$ penicillin and streptomycin (Sigma). Healthy oral gingival specimens were collected from patients aged 22-35 years at Chiba University Hospital. Five independent HNOK cell lines were cultured and maintained in defined keratinocyte-SFM (Gibco BRL, Gaithusberg, Germany) (7).

Protein and $m R N A$ extraction. Protein was extracted from the cells when they reached $80-90 \%$ confluence; they were washed twice with phosphate-buffered saline (PBS), scraped into a tube, and centrifuged briefly. The cell pellets were incubated for $30 \mathrm{~min}$ in a lysis buffer (LB) containing $7 \mathrm{M}$ urea, $2 \mathrm{M}$ thiourea, $4 \% \mathrm{w} / \mathrm{v}$ CHAPS, and $10 \mathrm{mM}$ Tris $\mathrm{pH} 8.0$, and lysed by sonication $(3 \times 10 \mathrm{sec}$ pulses on ice). After the sample was centrifuged at 13,000 rpm for $20 \mathrm{~min}$, the supernatant containing the cell proteins was recovered, and the protein concentration was measured with a Protein Assay Kit (BioRad Laboratories, Hercules, CA, USA) and adjusted to $1 \mathrm{mg} / \mathrm{ml}$ with $\mathrm{LB}$. The $\mathrm{pH}$ of the protein sample was adjusted to 8.5 with $30 \mathrm{mM}$ Tris-HCl. Total RNA was extracted using TRIzol Reagent (Invitrogen Life Technologies, Carlsbad, CA, USA), according to the manufacturer's instructions. Each specimen of extracted RNA was stored separately at $-80^{\circ} \mathrm{C}$ until use.

Immunofluorescence. Cells were plated on chamber slides at $50 \%$ confluency, washed with ice-cold PBS, and fixed with $1 \%$ paraformaldehyde-PBS for $20 \mathrm{~min}$, then permeabilized in PBS containing $0.2 \%$ Triton $\mathrm{X}-100$ as previously described (9). The following primary antibodies were used: polyclonal anti-Septin1 (Santa Cruz Biotechnology, Santa Cruz, CA,
USA) at 1:200 dilution for $2 \mathrm{~h}$, washed with PBS, and incubated with donkey anti-goat IgG secondary antibody labeled with Alexa Fluor 488 (Molecular Probes, Leiden, The Netherlands) for $2 \mathrm{~h}$. Coverslips were examined by fluorescence microscopy. The microscope used was a Leica DMIRBE inverted stand equipped with a Leica TCS2-MP confocal system (Leica Laserteknik, Mannheim, Germany) and Coherent Mira tunable pulsed titanium sapphire laser (Coherent Laser Group, Santa Clara, CA, USA).

Western blot analysis. Protein extracts were electrophoresed on $11 \%$ sodium dodecyl sulfate-polyacrylamide gel electrophoresis gels, transferred to polyvinylidene fluoride (PVDF) membranes (Bio-Rad), and blocked for $1 \mathrm{~h}$ at room temperature in 5\% skim milk. Immunoblot PVDF membranes were washed five times with $0.1 \%$ Tween-20 in TBS (TBS-T), and $2 \mu \mathrm{g} / \mathrm{ml}$ affinity-purified rabbit antihuman Septin1 polyclonal antibody (Abcam) was added directly to the TBS-T solution for $2 \mathrm{~h}$ at room temperature. PVDF membranes were washed again and incubated with a 1:700 of horseradish peroxidase-conjugated antigoat IgG Envision ${ }^{+}$(Dako Japan Inc., Kyoto, Japan) as a secondary antibody for $90 \mathrm{~min}$ at room temperature. Finally, the membranes were incubated with $\mathrm{ECL}^{+}$-horseradish peroxidase substrate solution included in the $\mathrm{ECL}^{+}$kit (Amersham Biosciences UK Ltd., UK), and immunoblotting was visualized by exposing the membrane to Hyperfilm (Amersham) $(10,11)$.

Immunohistochemistry. Immunohistochemical staining was performed on $4-\mu \mathrm{m}$ sections of paraffin-embedded specimens with the use of goat anti-human Septin 1 polyclonal antibody (Abcam). Briefly, after deparaffinization and hydration, the slides were treated with endogenous peroxidase in $0.3 \%$ hydrogen peroxide for $30 \mathrm{~min}$, after which the sections were blocked for $2 \mathrm{~h}$ at room temperature with $1.5 \%$ blocking serum (Santa Cruz Biotechnology) in PBS before reacting with anti-Septin 1 antibody (1:200 dilution) at room temperature in a moist chamber for $2 \mathrm{~h}$. Upon incubation with the primary antibody, the specimens were washed three times in PBS and treated with Envision reagent (Dako) followed by color development in 3,3'-diaminobenzidine tetrahydrochloride (Dako). Finally, the slides were lightly counterstained with hematoxylin, dehydrated with ethanol, cleaned with xylene, and mounted. As a negative control, duplicate sections were immunostained without exposure to primary antibodies. To quantitate the state of Septin1 expression, the mean percentage of positive tumor cells was determined in at least five random fields at magnification $\mathrm{x} 400$ in each section. The intensity of a Septin1-immunoreaction was scored as follows: 1+, weak; $2+$, moderate; and $3+$, intense. The percentage of positive tumor cells and the staining intensity were then multiplied to produce a Septin1-immunohistochemical staining score $(12,13)$. A Septin1-immunohistochemistry scores are calculated as follows: the Septin1-immunohistochemistry score $=(\%$ of positive tumor cells) $\mathrm{X}$ the staining intensity. Cases with a Septin 1 score $>130.25$ (the highest score for normal tissue) were defined as positive. These judgments were made by two independent pathologists, neither of whom had knowledge of the patients' clinical status. Statistical significance was evaluated by the Fisher's exact test or the Mann-Whitney $\mathrm{U}$ test. $\mathrm{P}<0.05$ was considered significant. 
A

HNOKs

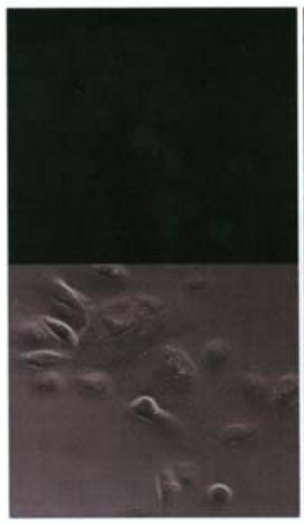

HSC-2
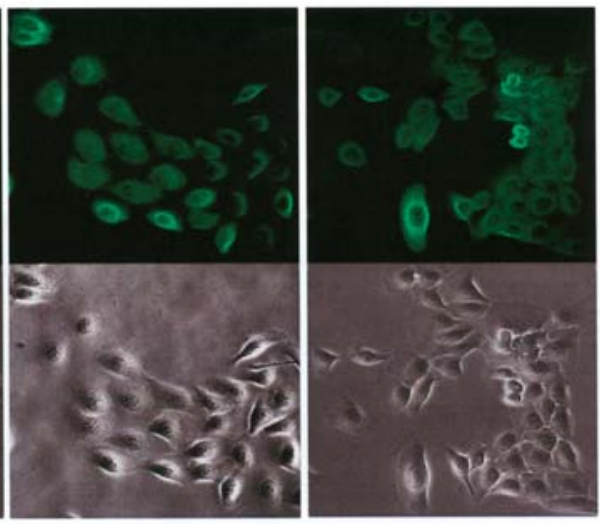

B

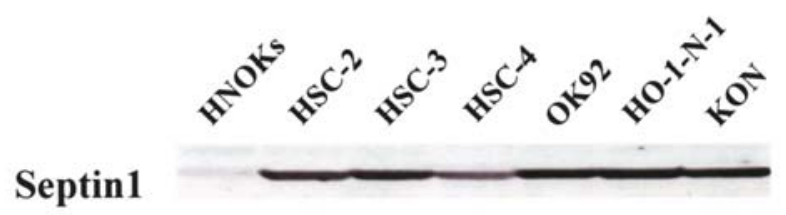

B-actin

C

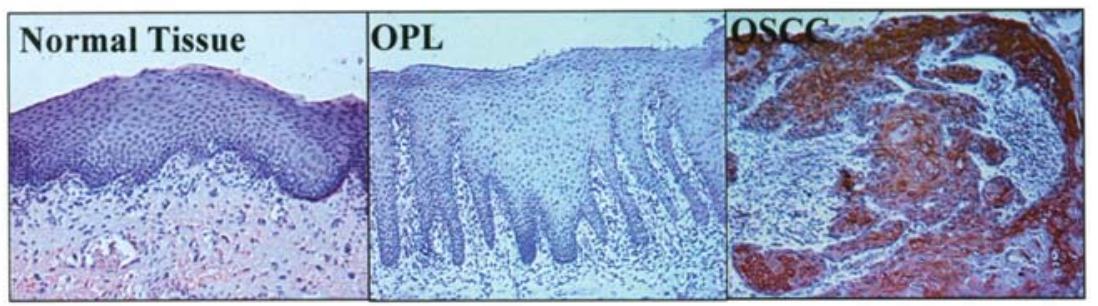

Figure 1. Septin1 expression in OSCC-derived cell lines. (A) Protein expression and subcellular localization of Septin1 in HNOks and OSCC-derived cell lines are identified by immunofluorescent staing. Septin1 is visualized with the antibody against Septin1 and Alexa Fluor 488 fragment of donkey anti-goat IgG. Immunocytochemical analysis shows strong immunoreactivity of Septin1 in OSCC-derived cell lines (HSC-2 and HSC-3) compared with the HNOKs. (B) Western blot analysis of Septin1 in OSCC-derived cell lines and HNOKs. HNOK extracts do not significantly express Septin1. OSCC-derived cell line extracts exhibiting Septin1 expression. (C) Immunohistochemical staining of Septin1 in normal and primary OSCCs. Normal oral tissue shows no Septin1 expression. The border between normal epithelium and the dysplastic lesion is seen. While no Septin1 expression is detected in normal epithelial and OPL cellular cytoplasms, strong Septin1 expression is evident in the lesion. Septin1-positive case of OSCCs. Strong positive immunoreaction for Septin1 is detected in the cytoplasm. Original magnification x200.

mRNA expression analysis. Among the OSCC cases studied by immunohistochemistry, expression levels of septin1 mRNA were examined in 52 patients with OSCC from whom mRNA was available from primary tumors and from paired specimens of normal oral tissue. Control reactions were prepared in parallel without reverse transcriptase. In addition, expression levels of septin1 mRNA were examined in OSCC-derived cell lines (HSC-2, HSC-3, HSC-4, OK92, HO-1-N-1, and KON) and in HNOKs. Real-time quantitative reverse transcriptasepolymerase chain reaction (QRT-PCR) was performed with a single method using a LightCycler FastStart DNA Master SYBR Green 1 Kit (Roche Diagnostics GmbH, Mannheim, Germany), according to the procedure provided by the manu- facturer. The primer sequences used to analyze septin1 mRNA expression were forward 5'-AGAACCCACATCACTGCGA TTT-3' and reverse 5'-TAGCCCTCGTAGAGCAGAGTCT-3'. The sequence of specific primers was checked before use to avoid amplification of genomic DNA or pseudogenes using the Primer3 program (http://www-genome.wi.mit.edu/cgibin/primer/primer3_www.cgi). The PCR reactions using LightCycler (Roche) apparatus were carried out in a final volume of $20 \mu \mathrm{l}$ of a reaction mixture consisting of $2 \mu 1$ of FirstStart DNA Master SYBR Green I mix (Roche), $3 \mathrm{mM}$ $\mathrm{MgCl}_{2}$, and $0.2 \mu \mathrm{l}$ of the primers, according to the manufacturer's instructions. The reaction mixture then was loaded into glass capillary tubes and subjected to an initial denaturation 
at $95^{\circ} \mathrm{C}$ for $10 \mathrm{~min}$, followed by 45 rounds of amplification at $95^{\circ} \mathrm{C}(10 \mathrm{sec})$ for denaturation, $63^{\circ} \mathrm{C}(10 \mathrm{sec})$ for annealing, and $72^{\circ} \mathrm{C}$ for extension, with a temperature slope of $20^{\circ} \mathrm{C} / \mathrm{sec}$, performed in the LightCycler. The transcript amount for the septinl gene was estimated from the respective standard curves and normalized to the glyceraldehyde-3-phosphate dehydrogenase (GAPDH) (forward 5'-CATCTCTGCCCCCT CTGCTGA-3' and reverse 5'-GGATGACCTTGCCCACAG CCT-3') transcript amount determined in corresponding samples.

Statistical analysis. The statistical significance of the gene expression levels between septinl-positive and septin1-negative cases was calculated with the Mann-Whitney U test. $\mathrm{P}<0.05$ was considered significant. Data are expressed as the means $( \pm \mathrm{SD})$ of two independent experiments with triplicate samples. The relation of protein expression and histological types of oral cancer was evaluated using the Mann-Whitney U test performed in SPSS 13.0 for Windows. Differences were considered significant at $\mathrm{P}<0.05$. The disease-free survival and overall survival probabilities were calculated using the Kaplan-Meier method. The long-rank statistic was used to test the difference in survival times between the groups.

\section{Results}

Analyses of protein expression of Septin1 in OSCC-derived cell lines. We previously showed up-regulation of Septin1 in OSCC-derived cell lines (HSC-3 and HSC-2) (7). We evaluated the state of Septin 1 expression in four OSCCderived cell lines (HSC-4, OK92, HO-1-N-1, and KON) by Western blot analysis. Representative results of the analysis are shown in Fig. 1B. As expected, the size of the band was detected at $42 \mathrm{kDa}$, and a significant increase in Septin 1 expression was observed in all OSCC-derived cell lines compared with the HNOKs. Western blot experiments confirmed the results from 2-D-DIGE analysis and protein identification by the mass spectrometry performed in our previous study (7).

Immunofluorescence. We examined the expression level of Septin1 based on the results of proteomic analyses by immunofluorescence analysis. Two OSCCs-derived cell lines and HNOKs were examined. Septin 1 in the OSCC-derived cell lines were surrounded by obvious green fluorescence; no fluorescence was seen in any HNOKs, indicating that the data matched the proteomic study. Fig. 1A shows a representative result of the immunofluorescence analysis.

Immunohistochemistry. A total of 85 patients with OSCC were identified for whom there was adequate histologic material available for immunohistochemical analysis. The correlation between the clinicopathologic characteristics of the patients with OSCCs and the status of Septin1 expression is summarized in Table I. Normal oral mucosa specimens had no significant down-regulation of Septin1 expression and were considered Septin1-negative. Among the tumors examined, 77 of 85 cases (89\%) had Septin 1 immunoreactivity in the cytoplasm of the tumor cells. Representative results for Septin1 expression in normal oral tissue and

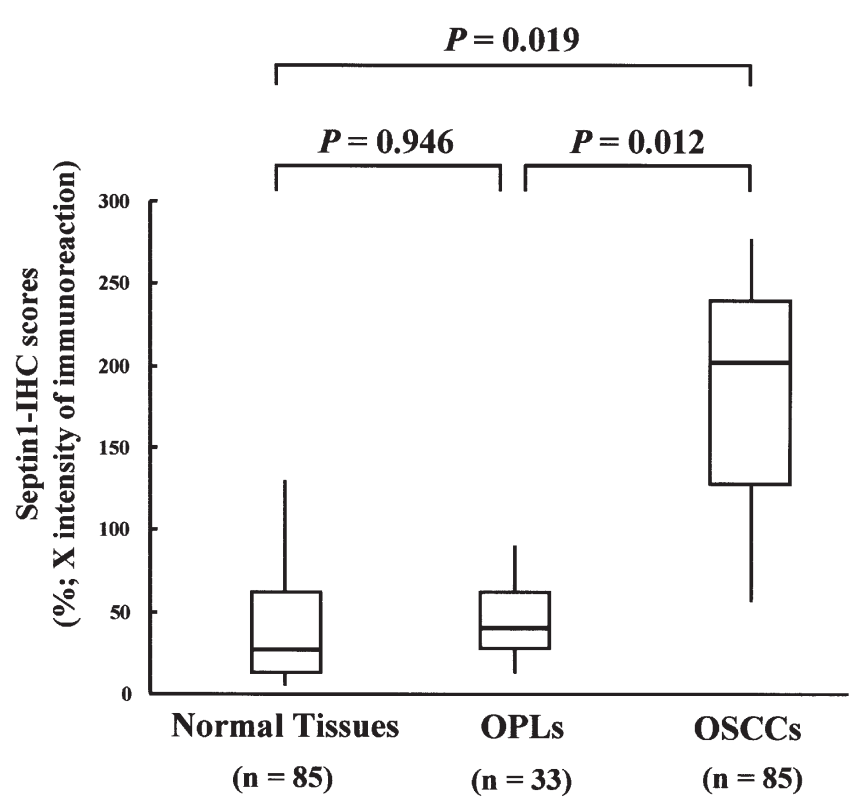

Figure 2. State of Septin1 expression in normal tissues $(n=85)$, OPLs $(n=33)$ and primary OSCCs $(n=85)$. Septin 1 expression in OSCCs is significantly higher than in normal oral tissues and OPLs (Mann-Whitney U test). The results represent the mean $\pm \mathrm{SD}$. IHC, immunohistochemistry.

primary OSCCs are shown in Fig. 1C. The Septin1 immunohistochemistry scores for normal tissues, OPLs and OSCCs ranged from 2.21 to 137.35 (mean 37.25 ), 19.29 to 91.27 (mean 43.57) and 50.36 to 275.0 (mean 203.8), respectively. Septin 1 expression levels in primary OSCCs were significantly higher than in normal oral tissues (Mann-Whitney U test, $\mathrm{P}<0.019$ ) (Fig. 2).

mRNA expression analysis. Septin1 mRNA expression levels were significantly increased in primary OSCCs $(n=52)$ compared with matched non-cacerous squamous samples $(\mathrm{n}=52)$ (Mann-Whitney U test, $\mathrm{P}<0.010$ ) (Fig. 3A). Relative mRNA expression levels in normal tissues, OPLs, and OSCCs ranged from 1.12 to 11.3 (mean 4.76), 1.24 to 5.26 (mean 2.57), and 3.18 to 39.1 (mean 15.74), respectively. A significant increase in the expression of septin1 occurred in all OSCC-derived cell lines examined compared with the HNOKs (Fig. 3B). Septin 1 mRNA expression levels for the HNOKs and OSCCderived cell lines ranged from 0.18 to 2.7 (mean 1.13) and 4.89 to 14.8 (mean 7.35), respectively. Therefore, septin1 mRNA expression levels were consistent with the protein expression status.

Influence of Septinl expression on patient's survival. The overall survival and disease-free survival rates for the patients with positive Septin1 expression were 84.9 and $79.8 \%$, respectively, and negative Septin1 expression was 81.4 and $68.3 \%$ respectively (log-rank test, $\mathrm{P}>0.05$ ) (Fig. 4). Survival analysis using the Kaplan-Meier method showed that in the group of high Septin1 expression the overall survival and disease-free survival were not significant compared with that of the group with low Septin1 expression. 
A

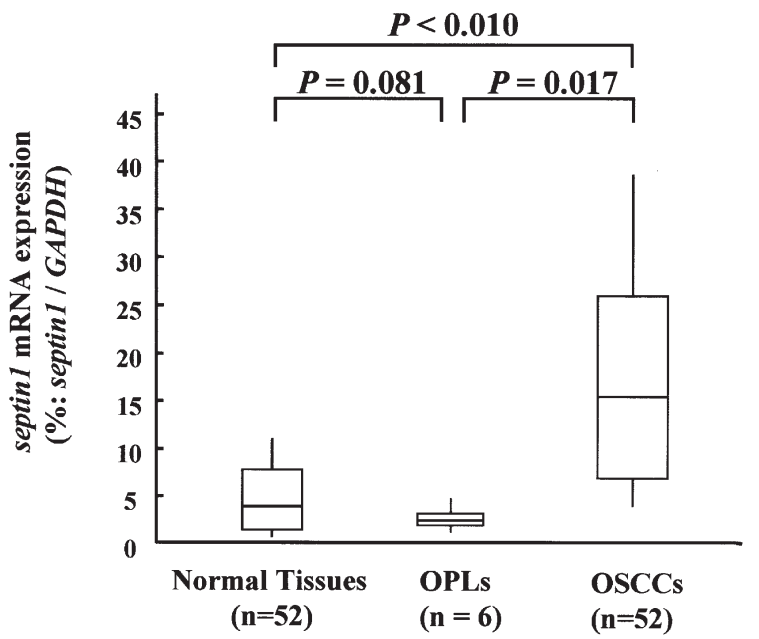

B

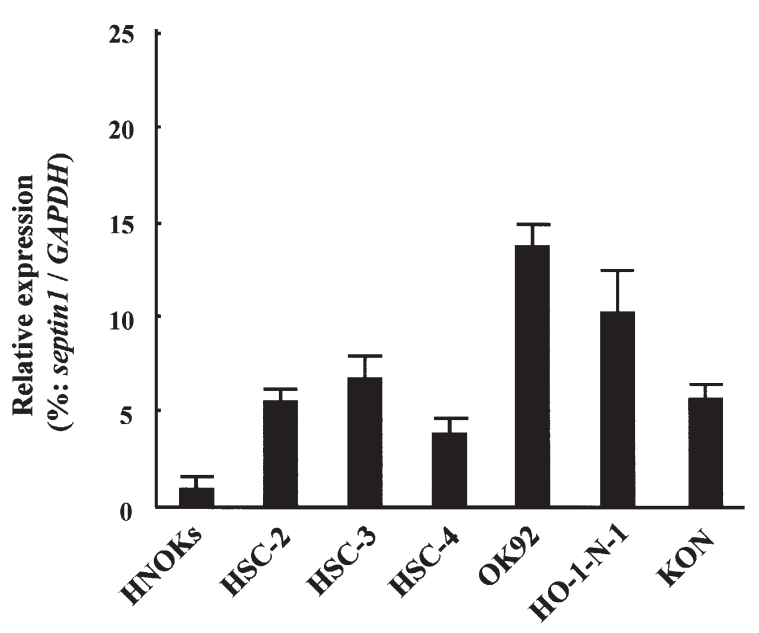

Figure 3. (A) State of septin1 mRNA expression in normal tissues $(n=52)$, OPLs $(n=6)$ and primary OSCCs $(n=52)$. Septin1 mRNA expression in OSCCs is significantly higher than in normal tissues and OPLs (MannWhitney U test). The results represent the mean \pm SD. (B) Septin1 mRNA expression status in primary OSCCs and OSCC-derived cell lines. Quantification of mRNA levels in OSCC-derived cell lines by real-time QRT-PCR analysis. Significant up-regulation of septin1 mRNA is seen in all OSCCderived cell lines compared to septin1 mRNA expression in HNOKs. Data are expressed as means $\pm \mathrm{SD}$.

\section{Discussion}

Because the functional molecules in cells are protein, proteome analysis based on 2-dimensional gel electrophoresis is believed to have several advantages over cDNA/oligonucleotide microarray systems for clinical use. Proteomic studies of clinical tumor samples identified cancer-specific protein markers, which provide a basis for developing new methods for early diagnosis and early detection and clues to understanding the molecular characterization of cancer progression (14-18). We recently reported that a significant increase in Septin1 expression was observed in OSCC-derived cell lines, using a 2-D-DIGE system and MALDI-TOF/MS (7).

Human Septins have been newly identified as a conserved family of GTPase proteins (19-28). Septin1 remains at the centrosomes and the nearby spindle region throughout mitosis and only appears at the cleavage furrow or the midbody in telophase and cytokinesis, when it partially co-localizes with
A

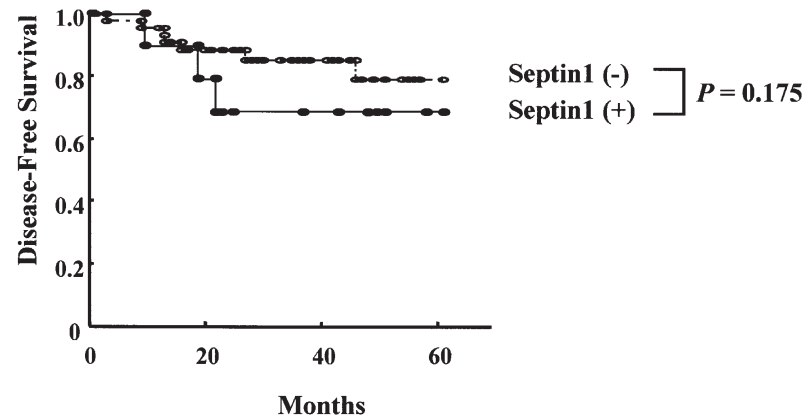

B

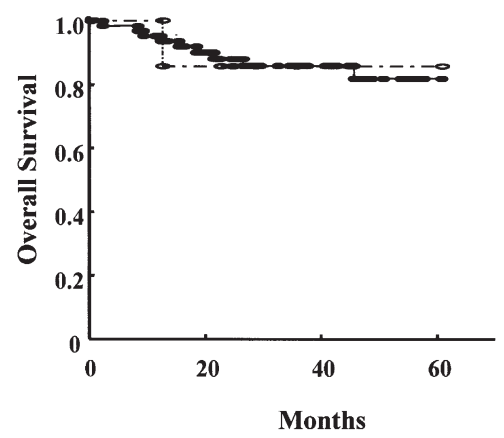
Septin1 (-)
Septin1 (+) $\square P=0.992$

Figure 4. Kaplan-Meier survival curve for disease-free survival and overall survival rate of patients with OSCCs according to the levels of Septin1 expression. High levels of Septin 1 expression are not significantly associated with lower disease-free survival (A) and overall survival (B) rates (A, $\mathrm{P}=0.175 ; \mathrm{B}, \mathrm{P}=0.992$, respectively). The log-rank statistic was used to test the difference in survival times between the groups. There is no significance difference between survival and disease rate when Septin1 overexpression was observed.

Aurora-B. Septin1's role in the regulation of cytokinesis is related to its phosphorylation by Aurora-B (29). Aurora-B is a 'chromosomal passenger' protein that localizes to centromeres from prophase to metaphase, to the midzone of the mitotic spindle in anaphase, and to the midbody in telophase (30). Aurora-B plays a crucial role in chromosome segregation and cytokinesis $(31,32)$. Overexpression of Aurora-B has been reported in several human cancer cell lines and in primary tumors including colorectal cancer (33), seminomas (34), thyroid anaplastic carcinoma (35) and non-small cell lung carcinoma (36). Based on the above evidence (29,33-36), we have hypothesized that overexpression of Septin 1 is correlated with the activator of Aurora B members of chromosomal passenger protein and contributed to the development of carcinogenesis. We suggested that overexpression of Septin 1 might contribute to the development of OSCCs. At present, status of Septin 1 in OSCCs remains unclear and for this reason we selected Septin 1 for further investigation.

To clarify the relative status of Septin 1 in OSCCs, we investigated septin 1 protein/mRNA expression in a series of OSCC-derived cell lines and human primary OSCCs using immunofluorescence, Western blot analysis, real-time QRTPCR, and immunohistochemistry. Significant increases in septin 1 protein/mRNA expression levels were observed in the OSCC-derived cell lines examined compared with the 
HNOKs. We also found that the vast majority of the OSCCs (77 of 85 samples) showed strong tumor cell-localized cytoplasmic Septin1-immunoreaction. Moreover, by evaluating the Septin1 immunohistochemistry scores using the MannWhitney U test, a significant up-regulation of Septin1 was observed in primary OSCCs $(\mathrm{P}=0.019)$ compared with normal tissues and OPLs, and real-time QRT-PCR analysis data were matched to protein expression levels. In contrast, we could not find any significant correlation between Septin1 overexpression and clinicopathologic features with the exception of tumor differentiation $(\mathrm{P}=0.0168)$. Thus, we speculate that Septin1 overexpression is not a prognostic marker but is a key event in the development of OSCCs. Further studies with a greater number of clinical material will be needed to address more detailed status of Septin1 in oral carcinogenesis.

Based on our data, we conclude that Septin1 is frequently overexpressed in OSCCs, but, not in OPLs, and thus Septin1 may also play an important role in the course of oral tumorigenesis. Follow-up studies are required to determine whether this reflects a non-causative role of Septin1 expression changes or a more complex involvement in the etiology of OSCCs and may lead to the development of new approaches for effective diagnosis and therapy.

\section{Acknowledgments}

This study was partly supported by a Grant-in-Aid Scientific Research (No. 16209059) from the Ministry of Education, Culture, Sports, Science and Technology of Japan. We thank Lynda C. Charters for editing this manuscript.

\section{References}

1. Lippman SM, Sudbo J and Hong WK: Oral cancer prevention and the evolution of molecular-targeted drug development. J Clin Oncol 23: 346-356, 2005.

2. Larsson T, Bergstrom J, Nilsson C and Karlsson KA: Use of an affinity proteomics approach for the identification of lowabundant bacterial adhesions as applied on the Lewis (b)-binding adhesion of Helicobacter pylori. FEBS Lett 469: 155-158, 2000.

3. Charlwood J, Skehel JM and Camilleri P: Analysis of N-linked oligosaccharides released from glycoproteins separated by twodimensional gel electrophoresis. Anal Biochem 284: 49-59, 2001.

4. Wilkins MR, Sanchez JC, Gooley AA, Appel RD, HumpherySmith L, Hochstrasser DF and Williams KL: Progress with proteome projects: why all proteins expressed by a genome should be identified and how to do it. Biotechnol Genet Eng Rev 13: 19-50, 1996.

5. Pandey A and Mann M: Proteomics to study genes and genomes. Nature 405: 837-846, 2000.

6. Rudert F: Genomics and proteomics tools for the clinic. Curr Opin Mol Ther 2: 633-642, 2000.

7. Koike H, Uzawa K, Nakashima D, Shimada K, Kato Y, Higo M, Kouzu Y, Endo Y, Kasamatsu A and Tanzawa H: Identification of differentially expressed proteins in oral squamous-cell carcinoma using a global proteomic approach. Int J Oncol 27: 59-67, 2005.

8. Takahashi K, Kanazawa H, Akiyama Y, Tazaki S, Takahara M, Muto T and Sato K: Establishment and characterization of a cell line (SAS) from poorly differentiated human squamouscell carcinoma of the tongue. J Jpn Stomatol Soc 38: 20-28, 1989.

9. Skoufias DA, Mollinari C, Lacroix FB, Wilson L and Margolis RL: Human survivin is a kinetochore-associated passenger protein. J Cell Biol 151: 1575-1581, 2000.
10. Endo Y, Uzawa K, Mochida Y, Shiiba M, Bukawa H, Yokoe H and Tanzawa H: Sarcoendoplasmic reticulum $\mathrm{Ca}(2+)$ ATPase type 2 downregulated in human oral squamous-cell carcinoma. Int J Cancer 110: 225-231, 2004

11. Kasamatsu A, Uzawa K, Nakashima D, Koike H, Shiiba M, Bukawa H, Yokoe $\mathrm{H}$ and Tanzawa $\mathrm{H}$ : Galectin-9 as a regulator of cellular adhesion in human oral squamous-cell carcinoma cell lines. Int J Mol Med 16: 269-273, 2005.

12. Shimada K, Uzawa K, Kato M, Endo Y, Shiiba M, Bukawa H, Yokoe H, Seki N and Tanzawa H: Aberrant expression of RAB1A in human tongue cancer. Br J Cancer 92: 1915-1921, 2005.

13. Tanaka C, Uzawa K, Shibahara T, Yokoe H, Noma H and Tanzawa H: Expression of an inhibitor of apoptosis, survivin, in oral carcinogenesis. J Dent Res 82: 607-611, 2003.

14. Hanash SM, Strahler JR, Kuick R, Chu EHY and Nichols D: Identification of a polypeptide associated with the malignant phenotype in acute leukemia. J Biol Chem 263: 12813-12815, 1988.

15. Hanash SM: Biomedical applications of two-dimensional electrophoresis using immobilized $\mathrm{pH}$ gradients: current status. Electrophoresis 21: 1202-1209, 2000.

16. Prasannan L, Misek DE, Hinderer R, Michon J, Geiger JD and Hanash SM: Identification of B-tubulin isoforms as tumor antigens in neuroblastoma. Clin Cancer Res 6: 3949-3956, 2000 .

17. Liotta L and Petricoin E: Molecular profiling of human cancer. Nat Rev Genet 1: 48-56, 2000.

18. Emmert-Buck MR, Gillespie JW, Paweletz CP, Ornstein DK, Basrur V, Appella E, Wang QH, Huang J, Hu N, Taylor P and Petricoin EF: An approach to proteomic analysis of human tumors. Mol Carcinog 27: 158-165, 2000.

19. Kinoshita M, Kumar S, Mizoguchi A, Ide C, Kinoshita A, Haraguchi T, Hiraoka Y and Noda M: Nedd5, a mammalian septin, is a novel cytoskeletal component interacting with actinbased structures. Genes Dev 11: 1535-1547, 1997.

20. Field CM and Kellogg D: Septins, cytoskeletal polymers or signalling GTPases? Trends Cell Biol 9: 387-394, 1999.

21. Hsu SC, Hazuka CD, Roth R, Foletti DL, Heuser J and Scheller RH: Subunit composition, protein interactions, and structures of the mammalian brain sec6/8 complex and septin filaments. Neuron 20: 1111-1122, 1998.

22. Kinoshita M, Field CM, Coughlin ML, Straight AF and Mitchison TJ: Self- and actin-templated assembly of mammalian septins. Dev Cell 3: 791-802, 2002.

23. Joberty G, Perlungher RR, Sheffield PJ, Kinoshita M, Noda M, Haystead $\mathrm{T}$ and Macara IG: Borg proteins control septin organisation and are negatively regulated by $\mathrm{Cdc} 42$. Nat Cell Biol 3: 861-866, 2001.

24. Xie H, Surka M, Howard J and Trimble WS: Characterization of the mammalian septin H5: distinct patterns of cytoskeletal and membrane association from other septin proteins. Cell Motil Cytoskeleton 43: 52-62, 1999.

25. Zhang J, Kong C, Xie H, McPherson PS, Grinstein S and Trimble WS: Phosphatidylinositol polyphosphate binding to the mammalian septin $\mathrm{H} 5$ is modulated by GTP. Curr Biol 9: 1458-1467, 1999.

26. Nagata KI, Kawajiri A, Matsui S, Takagishi M, Shiromizu T, Saitoh N, Izawa I, Kiyono T, Itoh TJ, Hotani H and Inagaki M: Filament formation of MSF-A, a mammalian septin, in mammary HMEC cells depends on interactions with microtubules. J Biol Chem 278: 18538-18543, 2003.

27. Surka MC, Tsang CW and Trimble WS: The mammalian septin MSF localizes with microtubules and is required for completion of cytokinesis. Mol Biol Cell 13: 3532-3545, 2002.

28. Beites CL, Xie H, Bowser R and Trimble WS: The septin CDCrel-1 binds syntaxin and inhibits exocytosis. Nat Neurosci 2: 434-439, 1999.

29. Meiyan Q, Wenbo Y, Shen L, Huijue J, Lisha T, Mingjuan S, Xiaomei Y, Hexige S, Qingyu L, Bo W, Shouyuan Z and Long Y: Septin1, a new interaction partner for human serine/threonine kinase aurora-B. Biochem Biophys Res Commun 336: 994-1000, 2005

30. Murata-Hori M, Tatsuka M and Wang YL: Probing the dynamics and functions of Aurora-B kinase in living cells during mitosis and cytokinesis. Mol Biol Cell 13: 1099-1108, 2002.

31. Terada Y, Tatsuka M, Suzuki F, Yasuda Y, Fujita S and Otsu M: AIM-1: a mammalian midbody-associated protein required for cytokinesis. EMBO J 17: 667-676, 1998. 
32. Schumacher JM, Golden A and Donovan PJ: AIR-2: an Aurora/ Ipl1-related protein kinase associated with chromosomes and midbody microtubules is required for polar body extrusion and cytokinesis in Caenorhabditis elegans embryos. J Cell Biol 143: 1635-1646, 1998.

33. Bischoff JR, Anderson L, Zhu Y, Mossie K, Ng L, Souza B, Schryver B, Flanagan P, Clairvoyant F, Ginther C, Chan CS, Novotny M, Slamon DJ and Plowman GD: A homologue of Drosophila aurora kinase is oncogenic and amplified in human colorectal cancers. EMBO J 17: 3052-3065, 1998.

34. Chieffi P, Troncone G, Caleo A, Libertini S, Linardopoulos S, Tramontano D and Portella G: Aurora B expression in normal testis and seminomas. J Endocrinol 181: 263-270, 2004.
35. Sorrentino R, Libertini S, Pallante PL, Troncone G, Palombini L, Bavetsias V, Spalletti Cernia D, Laccetti P, Linardopoulos S, Chieffi P, Fusco A and Portella G: Aurora B overexpression associates with the thyroid carcinoma undifferentiated phenotype and is required for thyroid carcinoma cell proliferation. J Clin Endocrinol Metab 90: 928-935, 2005.

36. Smith SL, Bowers NL, Betticher DC, Gautschi O, Ratschiller D, Hoban PR, Booton R, Santibanes-Koref MF and Heighway J: Overexpression of aurora B kinase (AURKB) in primary nonsmall cell lung carcinoma is frequent, generally driven from one allele, and correlates with the level of genetic instability. $\mathrm{Br} \mathbf{J}$ Cancer 93: 719-729, 2005. 